\title{
A U-shaped association between depression and vigorous physical activity: A cross-sectional study in a cohort of police officers and staff in England
}

\author{
Rabeea Maqsood, * Sarah Buckingham* and Karyn Morrissey*
}

\begin{abstract}
Policing has become an increasingly sedentary occupation. At the same time, rates of depression are increasing across the police force. Vigorous physical activity (VPA) has been associated with decreasing rates of depression, yet studies of VPA in policing are limited. This study aimed to explore the prevalence of depression and examine its association with VPA in police officers and staff in England, further stratified by gender. A cross-sectional, secondary data analysis of the Airwave dataset was undertaken. The data were analyzed using descriptive statistics and multivariate logistic regression. Of 28,465 police officers and staff in England, 12\% reported having doctor-diagnosed depression and 25\% were physically inactive. Relative to being physically inactive, undertaking VPA for either four or seven days was significantly associated with having the lowest odds of reporting depression (OR 0.59, 95\% CI: $0.51-0.70, p<0.001)$ (OR 0.59, 95\% CI: $0.45-0.77, p<0.001$ ), respectively, suggesting a U-shaped/non-linear relationship. This relationship was also observed in the gender-stratification analysis. While the odds of reporting depression were significantly lower for men than women, VPA was significantly associated with reducing the odds of reporting depression slightly more in women (OR $0.43,95 \%$ CI: $0.27-0.67, p<0.001$ ) than in men (OR $0.50,95 \%$ CI: $0.33-0.75, p<0.01$ ), indicating women may be more likely to benefit from VPA than men. Vigorous physical activity may provide a protective effect against depression. To prevent the onset of depression in the target population, policy-makers should consider designing physical activity guidelines for police officers to promote VPA in the target population.
\end{abstract}

Key Words Occupational health; mental and physical health; police force; secondary data analysis; psychophysical health; gender disparity.

\section{INTRODUCTION}

Policing is regarded as one of the most stressful occupations globally (Santa Maria et al., 2018). Coupled with the organizational challenges (Fox et al., 2012; Garbarino et al., 2013), prolonged exposure to traumatic and violent events increases the vulnerability of police officers to mental health disorders (Karaffa et al., 2015) — which are recognized as a leading cause of retirement in this population (Fox et al., 2012).

The increasing depression rates among police officers have been extensively reported in numerous studies within an occupational stress framework (Lawson et al., 2012; Wang et al., 2010; Wickramasinghe et al., 2016). A survey by English and Welsh policing reported around $80 \%$ of police officers feeling stressed or anxious (Houdmont et al., 2020). Costing US $\$ 4,489$ annually per police officer in the United States, police officers with mental health problems have also been reported to have a significantly higher productivity loss (5.9\%) than police officers without any mental health issue (3.4\%) (Fox et al., 2012). Indicating depression-related gender disparities, a study reported a two-fold higher prevalence of depressive symptoms in female police officers $(12.5 \%)$ than in male police officers (6.2\%) (Violanti et al., 2009). Overall, this emphasizes the importance of timely assistance of police officers battling with depressive symptoms (Garbarino et al., 2013). 
Traditionally, police work has been associated with physical fitness. However, with the increase in hybrid crimes and especially cybercrimes (Caneppele \& Aebi, 2017), police officers are becoming less physically active (Lagestad \& Tillaar 2014). Increasingly recognized as a preventive tool for clinical depression (Lambert et al., 2016), physical activity (PA) may mitigate the rising depression rates among police officers. The positive impact of PA on physical and mental health is well established (Noh et al., 2015). In addition to reducing depression (Azevedo et al., 2012) and improving depressive mood (Noh et al., 2015), PA has also been associated with improving life satisfaction, psychological well-being, and cognitive functions (Carek, Laibstain \& Carek, 2011).

Research examining the impact of PA on depression in the police force has been limited. Previous research has reported a non-linear or U-shaped association between depression and PA in both occupational (Kuwahara et al., 2015) and nonoccupational settings (Kim et al., 2018; Wise et al., 2006). These studies found no further reduction in depressive symptoms after reaching a threshold of PA level, indicating a complex association between depression and PA (Wise et al., 2006). In response, this study sought to explore the prevalence of depression and its association with vigorous physical activity (VPA) in police officers and staff in England.

\section{METHODS}

This study was a cross-sectional secondary data analysis of the data from the Airwave Health Monitoring study, an ongoing longitudinal study (Airwave Health Monitoring Study, n.d.). As the Terrestrial Trunked Radio (TETRA) is used for radio communication by the British police forces, the Airwave Health Monitoring study primarily aims at evaluating the impact of TETRA usage on health. Launched in 2004, the Airwave Health Monitoring study constitutes the largest cohort dataset on the police forces in the United Kingdom. At the end of the baseline recruitment in March 2015, 53,114 police officers and staff from the United Kingdom were recruited. A range of health and well-being data were collected from both radio users, and non-users from more than 50 clinics across the United Kingdom. The recruitment of participants and data collection has been described in detail elsewhere (Elliott et al., 2014).

The present study focused on police forces in England, as this constituted the highest number of participants $(n=$ $28,465,69.4 \%$ ) in the dataset. The data collected between 2004 and 2015 were used for the present study. Responses for the variables of interest were collected through a touchscreenbased questionnaire administered to the participants by the Airwave team (Elliott et al., 2014).

In this study, participants were categorized into the organizational positions of "inspectors/chief-inspectors/superintendent/above," "police constables/sergeants," "police staff," and "'others." In the UK police forces, chief constable and special constable are the highest and lowest ranks, respectively (Cambridgeshire Constabulary, n.d.). The absence of an internal hierarchy of "police staff" and definition of "others" in the Airwave dataset limited the understanding of these police roles in this study.

The outcome variable selected was self-reported doctordiagnosed depression, herein referred to simply as depression, with participants asked, "Have you ever been diagnosed by a doctor with depression?" The responses were either "Yes" or "No." Owing to the absence of clinical measures of depression in the Airwave dataset, self-reported depression was used. Regarding the validity of self-reported measures, research has found that self-reported data is a valid method to capture the health outcomes in epidemiology (Morrissey, 2016). As such, self-reported doctor-diagnosed depression is a widely used measure of depression (Bishwajit et al., 2017; Morrissey, 2016). A police study has also used a self-reported measure of depression to study depression in police officers (Wang et al., 2010).

The main explanatory variable-the number of days of VPA in the preceding week, hereafter VPA-was used as a proxy for VPA (Bishwajit et al., 2017). Participants were asked, "During the last 7 days, on how many days did you do vigorous physical activities?" using the International Physical Activity Questionnaire (IPAQ). The IPAQ is a self-report questionnaire which has been used internationally to measure PA levels in adult populations aged 15 to 69 years (Cleland et al., 2018). Researchers suggest that the IPAQ is better implemented when used in larger studies than on individual level studies for within or cross-country comparisons of groups for PA levels (Cleland et al., 2018). Regarding the selection of VPA, recalling PA over the previous 7 days has been used as a standard method for estimating typical PA levels (Bishwajit et al., 2017). This selection was also guided by previous research which reports that VPA is significantly associated with reducing depressive symptoms (Noh et al., 2015; Wise et al., 2006). The Metabolic Equivalent of Task (MET) could not be used due to a lower response rate than VPA.

From a temporal timeframe, we are linking measures taken from the previous 7 days (VPA) with measures that may have been diagnosed at any point in a participant's lifetime (doctor-diagnosed depression). However, self-reported PA in the preceding week has been used in existing studies to understand the association between PA and physical and mentalhealth outcomes, including self-reported doctor-diagnosed depression (Bishwajit et al., 2017). Indeed, a recent study used self-reported doctor-diagnosed depression and self-reported VPA to study the association between PA and depression among adults in South Asia using the World Health Survey data from the World Health Organization (Bishwajit et al., 2017).

Covariates included age, gender, marital status, organizational position, smoking and alcohol consumption. The inclusion of covariates was guided by previous research in which marital status, smoking, alcohol consumption (Karaffa et al., 2015), and organizational position (Garbarino et al., 2013) have been associated with depression and considered as confounding variables when exploring the association between depression and PA (Kuwahara et al., 2015; Noh et al., 2015). The gender stratification analysis was performed to explore depression-related gender differences and the impact of VPA in the current sample, guided by previous research (Violanti et al., 2009).

Statistical analysis was performed using the statistical package Stata/SE 15.1 (64 bit). Descriptive data analyses, including mean, standard deviation (SD), frequency $(n)$, and range, were employed to study the socio-demographic profile of the participants. To study the relationship between the outcome variable (depression) and explanatory variable (VPA) 
and covariates (age, gender, marital status, organizational position, smoking, and alcohol consumption), univariate and multivariate logistic regression was used. The outcome of this analysis was reported as odds ratios (OR) with 95\% confidence intervals (CI), where the level of significance was set at 5\%.

Three multivariate logistic models were run. The first model was adjusted for age, gender, and marital status. The second model was adjusted for age, gender, marital status and organizational position. The third model was adjusted for age, gender, marital status, organizational position, smoking, and alcohol consumption. The model having the highest $\mathrm{R}^{2}$ value (representing the model fit) was selected as the final model to be used in the results. The gender-stratified models were run with the same covariates.

\section{RESULTS}

Descriptive statistics showed that of 28,465 participants, $62 \%$ were men. The average age of the sample was 41.1 years $(\mathrm{SD} \pm 9.0)$. Most participants were in the age band $>40$ to $\leq 60$ $(53 \%)$ and were married (59\%). Most participants (62\%) were police constables or sergeants. In terms of lifestyle factors, $9 \%$ of participants reported smoking and $35 \%$ reported consuming alcohol two or three times a week.

Twelve percent of participants reported having been diagnosed with depression by a doctor. Of all the participants, $4 \%$ engaged in VPA for 7 days of the week as opposed to $25 \%$ participants who were not physically active on any day. The average number of days per week for VPA was 2.38 (95\% CI: 2.36-2.40). Men were slightly more physically active (average 2.55, 95\% CI: 2.52-2.58) than women (average 2.09, 95\% CI: 2.05-2.13) (Table I).

The univariate logistic regression analysis revealed that relative to participants who reported zero VPA in the preceding week, participants who engaged in VPA for 7 days had lower odds of reporting being diagnosed with depression by a doctor (OR 0.57, 95\% CI: 0.46-0.71). However, participants who did VPA for 4 days, had the lowest odds of reporting depression (OR 0.51, 95\% CI: 0.44-0.58) compared with participants with zero VPA.

The fully adjusted multivariate model showed that being physically active for either 4 days or 7 days a week was significantly associated with having the lowest odds of reporting depression compared with participants with zero VPA. Relative to respondents aged $\geq 17$ to $\leq 40$, respondents aged $>40$ to $\leq 60$ had the highest odds of reporting doctor-diagnosed depression. Compared with female respondents, male respondents had lower odds of reporting doctor-diagnosed depression. Relative to participants who cohabited, the odds of reporting depression were the highest for separated participants, followed by divorced participants. Compared with inspector/chief inspector/superintendent or above, those with the position of police staff had higher odds of reporting doctor-diagnosed depression, followed by police constables/ sergeants. Relative to non-smokers, smokers had higher odds of reporting doctor-diagnosed depression. With reference to participants who consumed alcohol daily or almost daily, participants who consumed alcohol two to four times a month had the lowest odds of reporting depression (Table II).

The gender-stratified analysis for male respondents showed that men who engaged in VPA on all 7 days of the
Table I Descriptive statistics of participants

\begin{tabular}{|c|c|c|}
\hline Variable & Frequency $(n)$ & Percentage (\%) \\
\hline \multicolumn{3}{|l|}{ Gender $(n=28,465)$} \\
\hline Male & 17,801 & 62 \\
\hline Female & 10,664 & 37 \\
\hline \multicolumn{3}{|l|}{ Age $(n=28,465)$} \\
\hline Mean \pm SD (range) & $\begin{array}{c}41.1 \pm 9.0 \\
(17.62-74.81)\end{array}$ & \\
\hline$\geq 17$ to $\leq 40$ & 12,702 & 45 \\
\hline$>40$ to $\leq 60$ & 15,190 & 53 \\
\hline$>60$ & 573 & 2 \\
\hline \multicolumn{3}{|l|}{ Depression ( $n=28,398$ ) } \\
\hline With depression & 3,427 & 12 \\
\hline Without depression & 24,971 & 88 \\
\hline \multicolumn{3}{|c|}{ Organizational position ( $n=24,732$ ) } \\
\hline $\begin{array}{l}\text { Inspector/Chief Inspector/ } \\
\text { Superintendent or above }\end{array}$ & 1,770 & 7 \\
\hline Police Constable/Sergeant & 15,327 & 62 \\
\hline Police staff & 7,160 & 29 \\
\hline Others & 475 & 2 \\
\hline \multicolumn{3}{|l|}{ Marital status ( $n=28,348$ ) } \\
\hline Cohabiting & 4,968 & 17 \\
\hline Divorced & 1,561 & 5 \\
\hline Married & 16,879 & 59 \\
\hline Other & 738 & 3 \\
\hline Separated & 814 & 3 \\
\hline Single & 3,388 & 12 \\
\hline \multicolumn{3}{|l|}{ Smoking ( $n=28,421)$} \\
\hline Yes & 2,490 & 9 \\
\hline No & 25,931 & 91 \\
\hline \multicolumn{3}{|l|}{ Alcohol consumption ( $n=25,659$ ) } \\
\hline Daily or almost daily & 1,972 & 8 \\
\hline Two or three times a week & 8,970 & 35 \\
\hline Four or five times a week & 3,079 & 12 \\
\hline Two to four times a month & 7,877 & 30 \\
\hline Monthly or less & 3,761 & 15 \\
\hline \multicolumn{3}{|c|}{ Vigorous Physical Activity ( $n=28,465$ ) } \\
\hline 0 & 7,092 & 25 \\
\hline 1 & 3,832 & 13 \\
\hline 2 & 4,724 & 17 \\
\hline 3 & 4,701 & 16 \\
\hline 4 & 3,373 & 12 \\
\hline 5 & 2,563 & 9 \\
\hline 6 & 1,152 & 4 \\
\hline 7 & 1,028 & 4 \\
\hline
\end{tabular}


Table II The multivariate logistic regression analysis results for police officers and staff in England

\begin{tabular}{|c|c|c|}
\hline Variable & Unadjusted model & Adjusted Model \\
\hline \multicolumn{3}{|l|}{ Vigorous physical activity } \\
\hline 0 & Reference & Reference \\
\hline 1 & $0.81^{* * *}(0.73,0.91)$ & $0.88(0.77,1.00)(\mathrm{NS})$ \\
\hline 2 & $0.69 * * *(0.62,0.77)$ & $0.75^{* * *}(0.66,0.85)$ \\
\hline 3 & $0.62 * * *(0.55,0.69)$ & $0.73^{* * *}(0.64,0.83)$ \\
\hline 4 & $0.51^{* * *}(0.44,0.58)$ & $0.59 * * *(0.51,0.70)$ \\
\hline 5 & $0.55^{* * *}(0.48,0.64)$ & $0.65^{* * *}(0.54,0.77)$ \\
\hline 6 & $0.52 * * *(0.42,0.65)$ & $0.65^{* * *}(0.50,0.84)$ \\
\hline 7 & $0.57^{* * *}(0.46,0.71)$ & $0.59 * * *(0.45,0.77)$ \\
\hline \multicolumn{3}{|l|}{ Age } \\
\hline$\geq 17$ to $\leq 40$ & Reference & Reference \\
\hline$>40$ to $\leq 60$ & $1.47^{* * *}(1.37,1.59)$ & $1.57^{* * *}(1.43,1.73)$ \\
\hline$>60$ & $1.25(0.97,1.62)(\mathrm{NS})$ & $1.23(0.90,1.67)(\mathrm{NS})$ \\
\hline \multicolumn{3}{|l|}{ Gender } \\
\hline Female & Reference & Reference \\
\hline Male & $0.37^{* * *}(0.35,0.40)$ & $0.42 * * *(0.38,0.46)$ \\
\hline \multicolumn{3}{|l|}{ Marital status } \\
\hline Cohabiting & Reference & Reference \\
\hline Divorced & $2.37^{\star * *}(2.05,2.75)$ & $1.88^{* * *}(1.57,2.24)$ \\
\hline Married & $0.90 *(0.81,0.99)$ & $0.90(0.80,1.02)$ (NS) \\
\hline Other & $1.28 *(1.02,1.60)$ & $1.19(0.91,1.56)(\mathrm{NS})$ \\
\hline Separated & $1.98 * * *(1.63,2.40)$ & $1.89 * * *(1.51,2.36)$ \\
\hline Single & $1.27^{* * *}(1.11,1.44)$ & $1.10(0.94,1.28)(N S)$ \\
\hline \multicolumn{3}{|l|}{ Organizational position } \\
\hline Inspector/Chief Inspector/Superintendent or above & Reference & Reference \\
\hline Other & $1.69 * *(1.22,2.34)$ & $1.35(0.94,1.93)(N S)$ \\
\hline Police constable/sergeant & $1.41^{* * *}(1.18,1.70)$ & $1.46^{* * *}(1.20,1.78)$ \\
\hline Police staff & $2.36^{* * *}(1.96,2.85)$ & $1.74^{* * *}(1.41,2.14)$ \\
\hline \multicolumn{3}{|l|}{ Smoking } \\
\hline Yes & $1.70 * * *(1.52,1.89)$ & $1.36 * * *(1.19,1.56)$ \\
\hline No & Reference & Reference \\
\hline \multicolumn{3}{|l|}{ Alcohol consumption } \\
\hline Daily or almost daily & Reference & Reference \\
\hline Two or three times a week & $0.66^{* * *}(0.57,0.75)$ & $0.65^{\star * *}(0.56,0.75)$ \\
\hline Four or five times a week & $0.78 * *(0.66,0.91)$ & $0.77^{* *}(0.64,0.91)$ \\
\hline Two to four times a month & $0.60 * * *(0.52,0.69)$ & $0.60 * * *(0.51,0.70)$ \\
\hline Monthly or less & $0.73 * * *(0.62,0.85)$ & $0.68 * * *(0.57,0.80)$ \\
\hline \multicolumn{3}{|l|}{$\begin{array}{l}{ }^{*} p<0.05 \\
{ }^{* *} p<0.01 \\
{ }^{* *} p<0.001 \\
(N S)=\text { Non-sign }\end{array}$} \\
\hline
\end{tabular}


week and consumed alcohol two or three times a week had the lowest odds of reporting depression, relative to their reference groups. Similar to the unstratified model, men aged $>40$ to $\leq 60$ who were: separated, positioned as police staff, and smokers had the highest odds of reporting depression when compared with their reference groups (Table III).

In contrast, female respondents showed slightly different results with VPA, marital status, and alcohol consumption. Women who performed a VPA 6 days a week and consumed alcohol only two to four times a month had the lowest odds of reporting depression. Moreover, women aged $>40$ to $\leq 60$ and those who were divorced, positioned as police staff, and smokers had the highest odds of reporting doctor-diagnosed depression, when compared with their reference groups (Table III).

\section{DISCUSSION}

Using the Airwave dataset, this study found that $12 \%$ of police officers and staff in England reported having doctordiagnosed depression. The multivariate logistic regression analysis found a significant non-linear (U-shaped) relationship between depression and VPA in the current sample, after adjusting for all confounding variables. With men having lower odds of reporting depression than women, women were more likely to benefit from VPA than men.

The estimated prevalence of depression in the current sample is higher $(12 \%)$ than that of English adults aged 18 or above $(9.9 \%)$ who participated in the Mental Health of Children and Young People in England survey in 2017-2018 (Public Health England, 2018) and GP-registered patients aged 18 (9.1\%) in 2016-2017 using the data from Quality and Outcomes Framework (QOF) (Health and Social Care Information Centre, 2017). Regarding research in policing, the $12 \%$ prevalence of depression in police officers and staff in England indicated by this study may be higher than in the police forces of the United States (9\%) (Fox et al., 2012) and Sri Lanka (10\%) (Wickramasinghe et al., 2016). In contrast, the estimated prevalence of depression in the current sample was relatively lower than the prevalence of job-related depression reported in the Australian police force (ranging 37.2\% to 65.5\%) (Lawson, Rodwell, \& Noblet, 2012) and British Civil Servants (19.9\%) (Azevedo et al., 2012).

The association between depression and VPA observed in this study is similar to previous studies, which report a significant association between VPA and lower odds of reporting depression in occupational (Azevedo et al., 2012) and non-occupational (Noh et al., 2015) settings. This association was also observed in gender-stratified analyses. Explaining this inverse relationship between depression and PA, physiological mechanism suggests that PA stimulates and increases the production of serotonin, a neurotransmitter, in the body, which reduces depressive symptoms (Lambert et al., 2016; Overdorf et al., 2016). With a similar pathway to antidepressant drugs (Lambert et al., 2016), PA can be used as the first-line treatment for mild to moderate depression functions (Carek, Laibstain \& Carek, 2011). Regarding the psychological mechanism, the self-efficacy hypothesis suggests that mood and self-confidence may be boosted after regular PA when an individual perceives PA as being a challenge (Azevedo et al., 2012).
Similar to studies on VPA (Wise et al., 2006) or PA (Kim et al., 2018; Kuwahara et al., 2015) and depression, this study found a non-linear relationship between VPA and depression in police officers and staff in England. The lowest odds of reporting depression were for those participants who performed VPA for either 4 or 7 days, indicating that being physically active for 4 days may be as beneficial against depression as being physically active for 7 days. The overreporting of PA levels by participants has also explained this U-shaped relationship in a non-occupational research setting (Wise et al., 2006).

This is the first study to explore the prevalence of selfreported doctor-diagnosed depression and its U-shaped association with VPA in police officers and staff in England. This exploratory research adds empirical evidence to the limited literature on the association between depression and VPA and highlights depression-related gender disparities within the context of police forces and their staff in England. Another strength is the inclusion of police staff, as the high prevalence of depression reported by this group highlights the importance of including both officers and staff in health promotion policies in the police force. Multiple confounding factors (e.g., socio-demographic and lifestyle factors, organizational position) were adjusted; the effect of VPA on depression remained, even after the adjustment. This study has a large sample size which improves the external validity and potential for generalizing the results more widely.

Regarding the study limitations, this was an opportunistic secondary data analysis of the Airwave dataset rather than a study specifically designed to examine the association between depression and VPA. Using a self-reported measure of depression is another limitation due to recall bias and unreliability of diagnosis (Kuwahara et al., 2015) especially when history of diagnosis (pre/post joining the police force) was unknown. This may have underrepresented police populations' mental ill-health burden. Another limitation was not reporting metabolic equivalents of task to quantify VPA, as these had a lower response rate. The cross-sectional study design with fewer participants undertaking VPA hampered the understanding of the causal relationship between depression and VPA. Excluding other potential confounders (e.g., lack of motivation, length of police service, salary) may have impacted the association between depression and VPA.

Regarding policy and practice implications, a significant association between depression and VPA suggests that the introduction of PA guidelines for police officers and staff in England may help to mitigate poor mental health outcomes. Considering the National Police Wellbeing Service (NPWS) to improve psychophysical well-being of police officers and staff (College of Policing, n.d.a), this study recommends augmenting police officers' fitness tests (College of Policing, n.d.b) with mental health assessment tasks. The current Job-Related Fitness Test (JRFT) involves a multistage 15-meter shuttle run which is based on the physiological demands of Personal Safety Training of police officers (College of Policing, n.d.b). Expanding the assessment would allow an evaluation of police officers' mental health post-recruitment, when they are exposed to stressful occupational challenges (Garbarino et al., 2013). Given the need for mental health interventions in English policing (Houdmont et al., 2020), interventions 
Table III The multivariate logistic regression analysis results for the gender-stratified sample of police officers and staff in England

\begin{tabular}{|c|c|c|c|c|}
\hline \multirow[t]{2}{*}{ Characteristic } & \multicolumn{2}{|c|}{ Unadjusted Model } & \multicolumn{2}{|c|}{ Adjusted Model } \\
\hline & Male & Female & Male & Female \\
\hline \multicolumn{5}{|l|}{ Vigorous physical activity } \\
\hline 0 & Reference & Reference & Reference & Reference \\
\hline 1 & $0.88(0.74,1.05)(N S)$ & $0.83^{*}(0.71,0.96)$ & $0.98(0.80,1.20)(N S)$ & $0.82 *(0.69,0.98)$ \\
\hline 2 & $0.74^{*}(0.63,0.88)$ & $0.70 * * *(0.60,0.81)$ & $0.85(0.70,1.04)$ (NS) & $0.69^{* * *}(0.58,0.82)$ \\
\hline 3 & $0.75^{*}(0.63,0.89)$ & $0.61^{* * *}(0.52,0.72)$ & $0.82 *(0.68,1.00)$ & $0.66^{* * *}(0.55,0.80)$ \\
\hline 4 & $0.58 * * *(0.48,0.71)$ & $0.55^{* * *}(0.45,0.66)$ & $0.67^{* *}(0.53,0.84)$ & $0.54^{* * *}(0.43,0.68)$ \\
\hline 5 & $0.57^{* * *}(0.46,0.71)$ & $0.74^{* *}(0.60,0.91)$ & $0.52 * * *(0.40,0.68)$ & $0.83(0.65,1.05)(\mathrm{NS})$ \\
\hline 6 & $0.69 *(0.52,0.91)$ & $0.55^{* *}(0.39,0.77)$ & $0.84(0.62,1.16)(\mathrm{NS})$ & $0.43^{* * *}(0.27,0.67)$ \\
\hline 7 & $0.50 * * *(0.35,0.71)$ & $0.79(0.59,1.06)(\mathrm{NS})$ & $0.50 * *(0.33,0.75)$ & $0.69 *(0.48,0.99)$ \\
\hline \multicolumn{5}{|l|}{ Age } \\
\hline$\geq 17$ to $\leq 40$ & Reference & Reference & Reference & Reference \\
\hline$>40$ to $\leq 60$ & $1.91^{* * *}(1.69,2.16)$ & $1.48^{* * *}(1.34,1.64)$ & $1.95^{* * *}(1.68,2.26)$ & $1.34^{* * *}(1.18,1.52)$ \\
\hline$>60$ & $1.82 * *(1.27,2.62)$ & $1.07(0.73,1.56)(\mathrm{NS})$ & $1.79 * *(1.17,2.76)$ & $0.88(0.57,1.37)(\mathrm{NS})$ \\
\hline \multicolumn{5}{|l|}{ Marital status } \\
\hline Cohabiting & Reference & Reference & Reference & Reference \\
\hline Divorced & $2.44^{* * *}(1.92,3.09)$ & $2.20 * * *(1.82,2.66)$ & $1.89 * * *(1.44,2.48)$ & $1.96^{* * *}(1.55,2.47)$ \\
\hline Married & $0.94(0.80,1.10)(N S)$ & $1.13^{*}(0.99,1.30)$ & $0.75^{* *}(0.63,0.90)$ & $1.06(0.90,1.24)(\mathrm{NS})$ \\
\hline Other & $0.97(0.63,1.49)(\mathrm{NS})$ & $1.29(0.98,1.69)(\mathrm{NS})$ & $0.90(0.54,1.50)(\mathrm{NS})$ & $1.38 *(1.00,1.90)$ \\
\hline Separated & $2.45^{* * *}(1.86,3.23)$ & $1.77^{* * *}(1.34,2.33)$ & $2.13^{* * *}(1.56,2.91)$ & $1.66^{* *}(1.21,2.27)$ \\
\hline Single & $0.98(0.77,1.25)(N S)$ & $1.22 *(1.04,1.43)$ & $0.99(0.75,1.30)(\mathrm{NS})$ & $1.19(0.99,1.44)(\mathrm{NS})$ \\
\hline \multicolumn{5}{|l|}{ Organizational position } \\
\hline $\begin{array}{l}\text { Inspector/Chief Inspector/ } \\
\text { Superintendent or above }\end{array}$ & Reference & Reference & Reference & Reference \\
\hline Other & $1.03(0.59,1.78)(\mathrm{NS})$ & $1.41(0.88,2.26)(\mathrm{NS})$ & $1.06(0.58,1.91)(\mathrm{NS})$ & $1.55(0.93,2.59)$ (NS) \\
\hline Police constable/ sergeant & $1.24^{*}(0.99,1.55)$ & $1.32(0.94,1.86)(\mathrm{NS})$ & $1.48 * *(1.16,1.88)$ & $1.48 *(1.03,2.14)$ \\
\hline Police staff & $1.64^{* * *}(1.28,2.10)$ & $1.59 *(1.14,2.23)$ & $1.86^{* * *}(1.42,2.43)$ & $1.73^{* *}(1.20,2.48)$ \\
\hline \multicolumn{5}{|l|}{ Smoking } \\
\hline Yes & $1.54^{* * *}(1.29,1.84)$ & $1.58^{* * *}(1.37,1.82)$ & $1.33^{* *}(1.08,1.64)$ & $1.38^{* * *}(1.16,1.64)$ \\
\hline No & Reference & Reference & Reference & Reference \\
\hline \multicolumn{5}{|l|}{ Alcohol consumption } \\
\hline Daily or almost daily & Reference & Reference & Reference & Reference \\
\hline Two or three times a week & $0.60 * * *(0.50,0.73)$ & $0.61^{* * *}(0.50,0.75)$ & $0.60 * * *(0.49,0.74)$ & $0.69^{* *}(0.55,0.86)$ \\
\hline Four or five times a week & $0.87(0.70,1.08)(\mathrm{NS})$ & $0.65^{* *}(0.51,0.83)$ & $0.86(0.68,1.09)(\mathrm{NS})$ & $0.67^{* *}(0.51,0.87)$ \\
\hline Two to four times a month & $0.62^{* * *}(0.51,0.75)$ & $0.49^{* * *}(0.40,0.60)$ & $0.66^{* * *}(0.53,0.82)$ & $0.55^{* * *}(0.44,0.70)$ \\
\hline Monthly or less & $0.57^{* * *}(0.45,0.73)$ & $0.61^{* * *}(0.49,0.76)$ & $0.68^{* *}(0.53,0.88)$ & $0.68^{* *}(0.53,0.86)$ \\
\hline $\begin{array}{l}{ }^{*} p<0.05 \\
{ }^{*} p<0.01 \\
{ }^{* \star} p<0.001 \\
\text { (NS) = Non-significant; Adjusted } \\
\text { model had the highest } R^{2} \text { value } c\end{array}$ & th & $\begin{array}{l}\text { Status, Organ } \\
\text { dels). }\end{array}$ & $D_{0}$ & this \\
\hline
\end{tabular}


including mobile health technology (e.g., wearable activity monitors) may be an effective way to promote PA in workplace settings (Buckingham et al., 2019) and subsequently to improve mental health. Such technology has been shown to be acceptable and impactful for increasing PA in the police force, particularly for less active officers and staff (Buckingham et al., 2020). While an economic assessment was not possible in this study, increasing opportunities for PA and assessing the police force's mental health more rapidly may result in fewer sick days and injuries, reducing productivity loss (Fox et al., 2012).

Future research requires longitudinal studies investigating the association between depression and VPA using objective measures of PA that are independent of participants' recall ability, ethnicity, and socioeconomic status and may further the understanding of the duration or intensity of PA that is most beneficial for the police force (College of Policing, n.d.b). Examining the dose-response relationship between depression and VPA is recommended to fully understand how different factors (e.g., frequency and duration of VPA) affect depression; this will help to understand the U-shaped relationship observed in this study. As restrictive factors, including high workload, lack of training facilities and recommendation by superior officers to do exercise in one's spare time, discourage police officers from PA (Lagestad \& Tillaar 2014), investigating the barriers to PA in the police work environment is also recommended. In conclusion, promoting PA in police officers and staff may prove to be a cost-effective way to prevent and treat depression by improving psychophysical well-being.

\section{ACKNOWLEDGEMENTS}

We are sincerely grateful to the team of Airwave Health Monitoring Study at Imperial College London for allowing the use of the Airwave dataset and to Prof. John Harrison at Devon and Cornwall Police for his support for this study. We would also like to acknowledge the Commonwealth Scholarship Commission in the UK for funding the Master's studies of RM at the University of Exeter.

\section{CONFLICT OF INTEREST DISCLOSURES}

Ethical approval was sought from the Research Ethics Committee (REC) of the University of Exeter Medical School, UK. The data from the Airwave Health Monitoring Study is not publicly available. For the purpose of this study, the team of the Airwave Health Monitoring Study at Imperial College London granted access to the dataset upon request by the authors. Only the authorized persons, e.g., RM, $\mathrm{KM}$, and SB used the data for this study. The confidentiality forms provided by the Airwave Health Monitoring Study team at Imperial College London were signed by the authors. The data may be requested from: https://police-health.org.uk/. The authors declare that they have no competing interests.

\section{AUTHOR AFFILIATIONS}

*European Centre for Environment and Human Health, University of Exeter Medical School, Knowledge Spa, Royal Cornwall Hospital, Truro, Cornwall, United Kingdom.

\section{REFERENCES}

Airwave Health Monitoring Study. (n.d.). Publications. Retrieved February 10, 2021, from https://police-health.org.uk/follow-screening

Azevedo, D. S. M., Singh-Manoux, A., Brunner, E. J., Kaffashian, S., Shipley, M. J., Kivimäki, M., \& Nabi, H. (2012). Bidirectional association between physical activity and symptoms of anxiety and depression:
The Whitehall II study. European Journal of Epidemiology, 27(7), 537-546.

Bishwaiit, G., O'Leary, D. P., Ghosh, S., Yaya, S., Shangfeng, T., \& Feng, Z. (2017). Physical inactivity and self-reported depression among middle- and older-aged population in South Asia: World health survey. BMC Geriatrics, 17, 100.

Buckingham, S., Williams, A., Morrissey, K., Price, L., \& Harrison, J. (2019). Mobile health interventions to promote physical activity and reduce sedentary behaviour in the workplace: A systematic review. Digital Health, 5, 2055207619839883.

Buckingham, S., Williams, A., Morrissey, K., Price, L., \& Harrison, J. (2020). The Physical Activity Wearables in the Police Force (PAW-Force) study: Acceptability and impact. BMC Public Health, 20, 1645.

Cambridgeshire Constabulary. (n.d.). Police Ranks. Retrieved February 10, 2021, from https://www.cambs.police.uk/information-and-services/ About-us/Police-ranks

Caneppele, S., \& Aebi, M. F. (2017). Crime drop or police recording flop? On the relationship between the decrease of offline crime and the increase of online and hybrid crimes. Policing: A Journal of Policy and Practice, 13(1), 66-79.

Carek, P. J., Laibstain, S. E., \& Carek, S. M. (2011). Exercise for the treatment of depression and anxiety. The International Journal of Psychiatry in Medicine, 41(1), 15-28

Cleland, C., Ferguson, S., Ellis, G., \& Hunter, R. F. (2018). Validity of the International Physical Activity Questionnaire (IPAQ) for assessing moderate-to-vigorous physical activity and sedentary behaviour of older adults in the United Kingdom. BMC Medical Research Methodology, 18(1), 176.

College of Policing. (n.d.a). Wellbeing. Retrieved February 10, 2021, from https://www.college.police.uk/What-we-do/Support/Healthsafety/Pages/Wellbeing.aspx

College of Policing. (n.d.b). Job-related Fitness Standards. Retrieved May 14 2021, from https://www.college.police.uk/support-forces/ health-safety-welfare/job-related-fitness-standards

Elliott, P., Vergnaud, A. C., Singh, D., Neasham, D., Spear, J., \& Heard, A. (2014). The Airwave health monitoring study of police officers and staff in Great Britain: Rationale, design and methods. Environmental Research, 134, 280-285.

Fox, J., Desai, M. M., Britten, K., Lucas, G., Luneau, R., \& Rosenthal, M. S. (2012). Mental-health conditions, barriers to care, and productivity loss among officers in an urban police department. Connecticut Medicine, 76(9), 525-531.

Garbarino, S., Cuomo, G., Chiorri, C., \&Magnavita, N. (2013). Association of work-related stress with mental health problems in a specia police force unit. British Medical Journal Open, 3(7), e002791.

Health and Social Care Information Centre. (2017). Quality and outcomes framework-prevalence, achievements and exceptions report 2017. Retrieved February 10, 2021, from https://files.digital.nhs.uk/ publication/c/r/qof-1617-rep.pdf

Houdmont, J., Jachens, L., Randall, R., Colwell, J., \& Gardner, S. (2020). Stress management competency framework in English policing. Occupational Medicine, 70(1):31-37.

Karaffa, K., Openshaw, L., Koch, J., Clark, H., Harr, C., \& Stewart C. (2015). Perceived impact of police work on marital relationships. The Family Journal: Counseling and Therapy for Couples and Families, 23(2), 120-131.

Kim, S. Y., Jeon, S. W., Shin, D. W., Oh, K. S., Shin, Y. C., \& Lim, S. W. (2018). Association between physical activity and depressive symptoms in general adult populations: An analysis of the dose-response relationship. Psychiatry Research, 269, 258-263.

Kuwahara, K., Honda, T., Nakagawa, T., Yamamoto, S., Akter, S., Hayashi, T., \& Mizove, T. (2015). Associations of leisure-time, occupational, and commuting physical activity with risk of depressive symptoms 
among Japanese workers: A cohort study. International Journal of Behavioral Nutrition and Physical Activity, 12(1), 119.

Lagestad, P., \& Tillaar, R. (2014). Longitudinal changes in the physical activity patterns of police officers. International Journal of Police Science \& Management, 16(1), 76-86.

Lambert, L., D'Cruz, A., Schlatter, M., \& Barron, B. (2016). Using physical activity to tackle depression: The neglected positive psychology intervention. Middle East Journal of Positive Psychology, 2(1), 42-60.

Lawson, K. J., Rodwell, J. J., \& Noblet, A. J. (2012). Mental health of a police force: Estimating prevalence of work-related depression in Australia without a direct national measure. Psychological Reports, 110(3), 743-752.

Morrissey, K. (2016). Gender differences in the association between common mental disorders and regional deprivation in Ireland. The Professional Geographer, 68(1), 129-137.

Noh, J.H., Lee, S. A., Choi, H. J., Hong, J. H., Kim, M. H., \& Kwon, Y. D. (2015). Relationship between the intensity of physical activity and depressive symptoms among Korean adults: Analysis of Korea Health Panel data. Journal of Physical Therapy Science, 27(4), 1233-1237.

Overdorf, V., Betty, K., Makarec, M., \& Szeles, C. A. (2016). The relationship between physical activity and depressive symptoms in healthy older women. Gerontology \& Geriatric Medicine, 2, 1-8.

Public Health England. (2018). Mental Health and Wellbeing JSNA 2018. Retrieved February 10, 2021, from https://fingertips.phe. org.uk/profile-group/mental-health/profile/mhisna/data\#page/0/ $\mathrm{gid} / 1938132922 / \mathrm{pat} / 6 / \mathrm{par} / \mathrm{E} 12000004 / \mathrm{ati} / 102 / \mathrm{are} /$ E06000015/iid/848/age/168/sex/4

Santa Maria, A., Wörfel, F., Wolter, C., Gusy, B., Rotter, M., Stark, S., Kleiber, D., \& Renneberg, B. (2018). The role of job demands and job resources in the development of emotional exhaustion, depression, and anxiety among police officers. Police Quarterly, $21(1), 109-134$

Violanti, J. M., Fekedulegn, D., Charles, L. E., Andrew, M. E., Hartley, T. A., Mnatsakanova, A., \& Burchfiel, C. M. (2009). Suicide in police work: Exploring potential contributing influences, American Journal of Criminal Justice, 34(1-2), 41-53.

Wang, Z., Inslicht, S. S., Metzler, T. J., Henn-Haase, C., McCaslin, S. E., Tong, H., Neylan, T. C., \& Marmar, C. R. (2010). A prospective study of predictors of depression symptoms in police. Psychiatry Research, 175(3), 211-216.

Wickramasinghe, N. D., Wijesinghe, P. R., Dharmaratne, S. D., \& Agampodi, S. B. (2016). The prevalence and associated factors of depression in policing: Across sectional study in Sri Lanka. Springerplus, 5(1), 1-9.

Wise, L. A., Adams-Campbell, L. L., Palmer, J. R., \& Rosenberg, L. (2006). Leisure time physical activity in relation to depressive symptoms in the black women's health study. Annals of Behavioral Medicine, $32(1), 68-76$. 